\title{
Electrochemical determination of antioxidant capacities in flavored waters by guanine and adenine biosensors
}

\author{
Ayman H. Kamel, Felismina T.C. Moreira, Cristina Delerue-Matos, M. Goreti F. Sales
}

\begin{abstract}
A B S T R A C T
The immobilization and electro-oxidation of guanine and adenine as DNA bases on glassy carbon electrode are evaluated by square wave voltammetric analysis. The influence of electrochemical pretreatments, nature of supporting electrolyte, $\mathrm{pH}$, accumulation time and composition of DNA nucleotides on the immobilization effect and the electrochemical mechanism are discussed. Trace levels of either guanine or adenine can be readily detected following short accumulation time with detection limits of 35 and $40 \mathrm{ng} \mathrm{mL}^{-1}$ for guanine and adenine, respectively.

The biosensors of guanine and adenine were employed for the voltammetric detection of antioxidant capacity in flavored water samples. The method relies on monitoring the changes of the intrinsic anodic response of the surface-confined guanine and adenine species, resulting from its interaction with free radicals from Fenton-type reaction in absence and presence of antioxidant. Ascorbic acid was used as standard to evaluate antioxidant capacities of samples. Analytical data was compared with that of FRAP method.
\end{abstract}

Keywords:

Guanine

Adenine

Voltammetry

Flavored waters

Antioxidant capacity

\section{Introduction}

Water is at the top of the ranking of the most consumed drinks all over the world. Bottling and commercializing water represents an important sector of the world economy. In search of consumer's preferences industries have applied several technical modifications to plain water. Today, a significant part of marketed water is flavored. These flavors and aromas added to water provide singular tastes and smells appreciated by men.

Flavoring compounds are added to foodstuffs to give taste and/or flavor (Council Directive 88/388/EEC). Addition of flavorings is followed up by the European Community to ensure that their consumption represents no danger to humans. In addition, flavorings are under continuous observation and must be re-evaluated whenever necessary in light of changing conditions of use or new scientific information. One main characteristic not yet explored at this "continuous observation" is their antioxidant capacity, an important feature at the prevention of multiple diseases.

Diet constitutes the main external contribution to body defenses against oxidative insult. It provides cells specific antioxidants that are able to scavenge multiple types of free radicals contributing to maintain cellular health (Mahal et al., 2001). A well-known flavor with free radical scavenging abilities is vanillin. It is a naturally occurring compound that scavenges hydroxyl, superoxide and 1,1-diphenyl-2-picrylhydrazyl (DPPH) free radicals (Liu and Mori, 1993). Vanillin is able to chemically repair both tryptophanyl and guanosinyl radicals (Mahal et al., 2001). Other flavors with reported antioxidant abilities are eugenol and isoeugenol (Atsumi et al., 2005). No other flavors were reported yet with regard to their antioxidant abilities.

All methods used for antioxidant capacity assessment follow the basic principle that an antioxidant inhibits the oxidation of a suitable substrate keeping the main features of this substrate and an appropriate measurement of the end-point (Arnao et al., 1999). After the substrate is oxidized under standard conditions, the extent of the oxidation (an end-point) is measured at a fixed time point or over the range that is characteristic of the generated free radical by optical measurements (Moreno, 2002). Examples of these are FRAP (Ferric ion reducing antioxidant power), TEAC (Trolox equivalent antioxidant capacity), ORAC (oxygen radical absorbance capacity) and TRAP (total radical trapping antioxidant parameter) methods. Each method has its own characteristics, and differences exist in free radical generating system, molecular target, end-point, time of residence in reaction medium, etc. (Serafini and Rio, 2004). Interpretation and comparison of their results is therefore complex. Furthermore, the protective effect exerted by antioxidant species (flavor) at the cellular level could only be achieved by monitoring the inhibition of DNA oxidative damage. Electrochemical meth- 
ods/techniques generally possess high sensitivity and have been used in the assessment of antioxidant capacities (Mello et al., 2006; Brainina et al., 2007; Buratti et al., 2007; Chevion et al., 2000).

In recent years, several electrochemical biosensors with an immobilized layer of DNA have been reported for the determination of electroactive and non-electroactive compounds interacting with DNA (Labuda et al., 2000; Mascini et al., 2001; Erdem and Ozsoz, 2002; Brett et al., 2002c) as well as detection of specific sequence of DNA (Wang and Kawde, 2001; Palecek and Fojta, 2001). DNA biosensors are also a sensitive tool for monitoring the DNA integrity.

In this work, electrochemical immobilization of purine bases on glassy carbon electrode is carried out to develop stable biorecognition layers for the voltammetric detection of antioxidant capacity of flavored water samples. Special emphasis is given to the study of the influence of experimental conditions on the immobilized layer and further electro-oxidation of the purine bases, such as the concentration of the immobilized compound, time of deposition, $\mathrm{pH}$, and nature of the buffer used for measurements.

The composition of the electrochemical screening system consisted in guanine or adenine layer on a glassy carbon electrode as oxidation target. A Fenton-type reaction was used to induce damage by $\bullet \mathrm{OH}$ radicals that can interact with guanine as well as adenine bases. The antioxidant properties of flavored waters were evaluated by measuring their protective role against oxidative damage by Square Wave Voltammetry.

\section{Materials and methods}

\subsection{Apparatus}

The electrochemical measurements were recorded using an Autolab PSTAT 10 potentiostat (Ecochemie, Netherlands) running on GPES software, and with a standard three electrode. The 663 VA Metrohm cell was equipped with a GCE (Metrohm $6.1204 .110,2.0 \mathrm{~mm}$ diameter), a platinum rod as an auxiliary electrode (Metrohm 6.1241.020, $2.0 \mathrm{~mm}$ diameter) and an $\mathrm{Ag} / \mathrm{AgCl}, \mathrm{KCl}$ $3.00 \mathrm{~mol} \mathrm{~L}^{-1}$ reference electrode (Metrohm 6.0728.010). A polishing kit (Metrohm 6.2802.010) was used to clean the electrode surface after each scan.

All pH measurements were carried out with a Crison $2002 \mathrm{pH}$ meter with a Sentek 71728 combined glass electrode. The electrode was calibrated with commercially available buffer reference solutions.

A Shimadzu UV-vis spectrophotometer (Model UV-1601) with 1.00 light path length and plastic cells were used for the absorbance measurements of the reference method.

\subsection{Reagents and solutions}

Guanine (Sigma), adenine (Sigma), ascorbic acid (Aldrich), iron (iii) chloride hexahydrate, acetic acid (Merck), $\mathrm{HCl}$ comercial (Carlo Erba), 2,4,6-Tris(2-pyridyl)-1,3,5-triazine (TPTZ, Fluka) were used throughout. Other chemicals were Merck pro-analysis grade and were used as received. All solutions were prepared with purified water (conductivity $<0.1 \mu \mathrm{S} \mathrm{cm}^{-1}$ ) obtained from a Millipore system.

Voltammetric measurements were carried out in $\mathrm{KNO}_{3}$, Tris, acetate, or phosphate solutions of $0.2 \mathrm{M}$ ionic strength as supporting electrolytes. Stock solutions of guanine or adenine were prepared by dissolving the appropriate amount of solid in $0.1 \mathrm{M}$ $\mathrm{NaOH}$ or $\mathrm{HCl}$, respectively, and diluting with water to the desired concentration. Working standard solutions were prepared daily by diluting the previous stock solution with the supporting electrolyte just before use. Ascorbic acid standard solutions were of
$100 \mathrm{mg} \mathrm{L}^{-1}$, and were prepared immediately before measurements. Fenton reaction for hydroxyl generation was carried out for a mixture of $9.9 \mathrm{mmol} \mathrm{L}^{-1} \mathrm{H}_{2} \mathrm{O}_{2}$ and $\mathrm{Fe}^{2+}\left(\mathrm{FeSO}_{4} \cdot 7 \mathrm{H}_{2} \mathrm{O}\right)$ in the presence of 1.0 mM EDTA over the $\mathrm{Fe}^{2+}$.

A 3-mM acetate buffer $\mathrm{pH} 3.6,10 \mathrm{mM}$ of TPTZ and $20 \mathrm{mM} \mathrm{FeCl}_{3}$ solutions were used for the FRAP method, used as comparison. TPTZ solutions were prepared in $40 \mathrm{mM} \mathrm{HCl}$ and dissolved at $50^{\circ} \mathrm{C}$ in a water bath. These solutions were daily prepared.

\subsection{Voltammetric measurements}

GCE $\left(0.07 \mathrm{~cm}^{2}\right)$ was polished to mirror finish using a polishing kit with $\gamma-\mathrm{Al}_{2} \mathrm{O}_{3}(0.015 \mu \mathrm{m})$. After rinsed with distilled water thoroughly, the electrode was applied a potential of $+1.70 \mathrm{~V}$ under stirring in $0.2 \mathrm{M}$ phosphate solution of $\mathrm{pH} 4.7$ for $300 \mathrm{~s}$, and then the electrode was scanned between +0.2 and $+1.4 \mathrm{~V}$ until a steadystate current-voltage curve was obtained. After this treatment, a thin blue film can be observed on the activated electrode surface. Supporting electrolyte or suitable buffer $(10.0 \mathrm{~mL})$ was placed in the electrochemical cell and purged with oxygen-free nitrogen for $300 \mathrm{~s}$. This solution was scanned in the positive direction [ from +0.2 to $+1.4 \mathrm{~V}$ ] to serve as blank. Different aliquots of guanine or adenine standard solutions was transferred to the electrochemical cell and purged with purified nitrogen for $300 \mathrm{~s}$. Another scan was made by keeping the same voltammetric conditions as those used in the blank. Voltammograms were recorded either immediately in quiescent solution or after adsorptive accumulation for a selected time at the predetermined potential in stirred solution. The equilibration period before each scan was $5 \mathrm{~s}$. All measurements were made in triplicate at room temperature. The main analytical features either the electrochemical or the chemical parameters were optimized, namely frequency, step potential, amplitude, supporting electrolyte composition and concentration, and $\mathrm{pH}$ by means of Cyclic Voltammetry (CV) and SWV. The peak heights were measured by "tangent fit".

\subsection{Preparation of the biosensor}

The electrode surface was pretreated by applying a potential of $+1.7 \mathrm{~V}$ for $30 \mathrm{~s}$ in acidic phosphate solution. The biosensor was developed by immobilizing the purine bases at fixed potential $(+0.4 \mathrm{~V}$ versus $\mathrm{Ag} / \mathrm{AgCl}$ electrode for $180 \mathrm{~s})$ onto the glassy carbon electrode surface. During the immobilization step, the electrode was immersed in phosphate solution containing $40 \mathrm{mg} \mathrm{L}^{-1}$ of the purine bases. Then a cleaning step was performed by immersion of the biosensor in a clean acidic phosphate solution, at open-circuit condition. The peak height of the purine peak was measured. Electrostatic binding of purine bases was achieved after applying an accumulation potential $\left(E_{\mathrm{acc}}\right)$ for a selected accumulation time $\left(t_{\mathrm{acc}}\right)$ to the electrode, while the solution was stirred. An accumulation step was required for each measurement.

The analytical response of the biosensor was assayed in buffer by applying a potential scan in the positive direction. Oxidation peak current was at its maximum because no chemical damaged was made. This corresponded to the blank signal of each biosensor (peak current $I_{0}$ ).

\subsection{Antioxidant capacity assays}

Hydroxyl radicals were generated by adding hydrogen peroxide into the non-stirred solution of iron and EDTA. The biosensor was placed in contact with radicals by immersing it in this mixture. Damage to purine base layer was made through diffusion of the radicals to the surface of the transducer. After a fixed period of time, the electrode was washed and immersed in buffer solution to obtain 
the biosensor response. Oxidative damage was evaluated after this under optimum SWV conditions.

The effect of antioxidants followed similar procedure. Ascorbic acid standard solutions were added to the cleavage mixture and the response of the biosensor indicated the protective effect from oxidative damage. Protective effects of antioxidants in samples were measured similarly by replacing the ascorbic acid by flavored waters. Four commercial brands were selected for this purpose, each having specific flavor composition (see Table 1). A natural water of each brand was used as control.

\subsection{FRAP method}

The reagent solution was prepared by mixing $100.0 \mathrm{ml}$ of $3 \mathrm{mM}$ acetate buffer, $10.0 \mathrm{ml}$ of $10 \mathrm{mM}$ TPTZ solution, and $10.0 \mathrm{ml}$ of $\mathrm{FeCl}_{3}$ solution. $1500 \mu \mathrm{l}$ of this mixture was added to $1300 \mu \mathrm{l}$ of acetate buffer and $200 \mu \mathrm{l}$ of water sample. The final solution was kept at $37^{\circ} \mathrm{C}$ in a water bath. Absorbance readings were conducted each 20 min until full signal stabilization.

\section{Results and discussion}

\subsection{Preparation of biosensor}

Pretreatment procedures are required to activate glassy carbon, especially when used for detection of biomolecules (McCreery and Cline, 1996). Short pre-treating periods were found to be essential for DNA adsorption at other carbon materials. Generally, this is made by anodization at about $+1.7 \mathrm{~V}$ (versus $\mathrm{AgCl} / \mathrm{Ag}$ reference electrode) (Wang et al., 2000; Cai et al., 1996). Response features of the electro-activated glassy carbon electrode depend however on the selected experimental conditions. The main variables affecting this process are the positive and negative potential limits to which the electrode is exposed, the composition and $\mathrm{pH}$ of the electrolyte solution, and the time of oxidation and reduction (Beilby et al., 1995).

In this work, the activation of the glassy carbon electrode was made in acidic phosphate solution by applying for $30 \mathrm{~s}$ the $+1.7 \mathrm{~V}$ versus the $\mathrm{AgCl} / \mathrm{Ag}$ reference electrode to ensure complete oxidation of any impurities adsorbed on the surface of the glassy carbon electrode. The current from guanine oxidation at the surface of an electrochemically activated glassy carbon electrode were much higher than those provided by a glassy carbon electrode that was just previously polished; the increase in peak current was higher than $100 \%$. Such pre-treatment appears to increase the hydrophilic character of the glassy carbon electrode surface, and hence to facilitate the adsorptive accumulation.

\subsection{Effect of pre-concentration period}

Only DNA bases adsorbed at the glassy carbon electrode will be in contact with radical species. Adsorption is achieved by an accumulation step carried out in acidic phosphate solution and under application of $+0.4 \mathrm{~V}$ versus $\mathrm{Ag} / \mathrm{AgCl}$ reference electrode. The time given for this accumulation step is an important parameter. Sensitivity of radical damage evaluations will increase when higher amounts of analyte are adsorbed.

As expected, the sensor response towards adenine and guanine was strongly dependent on the pre-concentration period. Fig. 1 (left) displays the SW voltammetric response for $4.9 \mathrm{mg} \mathrm{l}^{-1}$ guanine and $4.5 \mathrm{mg} \mathrm{l}^{-1}$ adenine after different pre-concentration periods from 10 to $240 \mathrm{~s}$. The longer the pre-concentration time, the more DNA nucleotides were adsorbed on the glassy carbon surface and the larger was the SWV response. As expected for adsorptioncontrolled processes, peak current increased rapidly with time at first and then leveled off. A 180 s was chosen as a pre-concentration period for subsequent measurements.

\subsection{Effect of background electrolyte}

The influence of different background electrolytes on the SW response of guanine and adenine biosensors is illustrated in Fig. 1 (centre). The higher signals were obtained using phosphate solution as supporting electrolyte, suggesting that specific interaction occurs with purine bases. Increasing signals, and thus increasing sensitivity, was observed for Tris $<$ acetate $<\mathrm{KNO}_{3}<$ phosphate solutions.

\subsection{Effect of $p H$}

Oxidation peak currents $\left(I_{\mathrm{p}}\right)$ decreased gradually as the $\mathrm{pH}$ increased (Fig. 2). The response reached its maximum at about $\mathrm{pH} 4-5$. Guanine and adenine oxidation peak potentials obeyed the equations, $E_{\mathrm{p}}=1.018-0.0565 \mathrm{pH}(r=-0.9861)$ and $E_{\mathrm{p}}=1.407-0.0688 \mathrm{pH}(r=-0.9704)$, respectively. The slopes of 56.6 and $68.8 \mathrm{mV} \mathrm{pH}^{-1}$ indicated that the number of protons in the ratedetermining step was equal to the number of electrons, i.e., two protons were involved (Brabec, 1981).

The oxidation of guanine and adenine on the surface of glassy carbon electrode followed a two-step mechanism (Scheme 1) involving the total loss of $4 \mathrm{e}^{-}$and the first $2 \mathrm{e}^{-}$oxidation step was rate-determining (Palecek, 1983).

\subsection{Effect of immobilized concentration}

The biosensor was prepared with solutions of different guanine or adenine concentrations, up to $70 \mathrm{mg} \mathrm{l}^{-1}$. Fig. 1 (right) displays a plot of guanine and adenine electro-oxidation signals after 3 min accumulation at $+0.4 \mathrm{~V}$; each point plot is to the average value of three experiments and the error bar is the standard deviation. Deviation to linear behavior was observed for adenine and guanine concentrations higher than 10 and $30 \mathrm{mg} \mathrm{l}^{-1}$, respectively. The data obtained by linear regression for each base, over the concentration range in which the peak current has a linear response with concentration, showed a linear range $0.15-25$ and $0.15-10 \mathrm{mg} \mathrm{L}^{-1}$ for guanine and adenine bases, respectively. Sensitivity and correlation coefficient of adenine and guanine linear responses were and $0.133 \mu \mathrm{ALmg}^{-1}$ and 0.990 , and $0.468 \mu \mathrm{ALmg}^{-1}$ and 0.993 , respectively. The corresponding detection limits were 0.04 and $0.035 \mathrm{mg} \mathrm{L}^{-1}$, using the formula $3 \times \mathrm{SD} /$ slope (Mocak et al., 1997).

SWV experiments were carried out in equimolar mixtures of each base, using a GCE that was electrochemically preconditioned. Concentrations ranged $0.3-10 \mathrm{mg} \mathrm{L}^{-1}$, in a $0.2 \mathrm{~mol} \mathrm{~L}^{-1}$ phosphate supporting electrolyte of $\mathrm{pH}$ 4.7. The resulting plots of peak current $\left(I_{\mathrm{p}}\right)$ versus concentration are given in Fig. 3. Linear responses for guanine and adenine DNA bases were observed within 0.2-3.0 and $0.25-3.0 \mathrm{mg} \mathrm{L}^{-1}$, respectively. Corresponding sensitivities were 4.30 and $1.96 \mu \mathrm{A} \mathrm{mg}^{-1}$, correlation coefficients 0.996 and 0.996 , and detection limits 0.05 and $0.07 \mathrm{mg} \mathrm{L}^{-1}$.

The $I_{\mathrm{p}}$-concentration plot gives information on the degree of interaction between each DNA base and the electrode surface and on lateral interactions between the DNA bases adsorbed on the surface. The guanine plot fitted well to Langmuir adsorption isotherm behavior (Laviron, 1982; Brett and Brett, 1993) and it was already found that a sub-monolayer of adsorbed guanine could be formed at the electrode surface at low concentration (Brett et al., 2002a). Contrarily, the $I_{\mathrm{p}}$-concentration plot obtained for adenine fitted better a Temkin adsorption isotherm in which it is considered that the adsorption sites at the surface are not all equivalent due to surface 

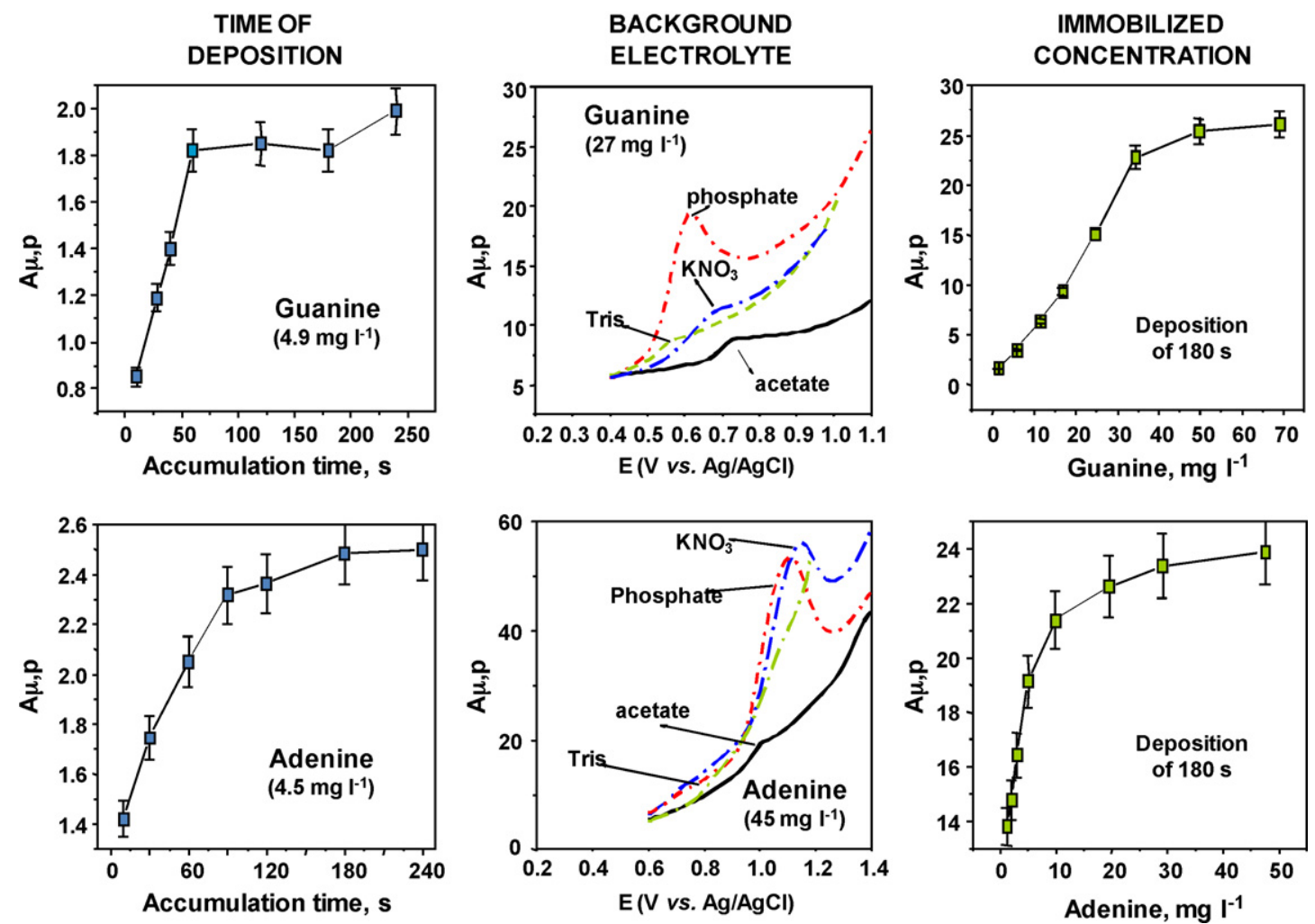

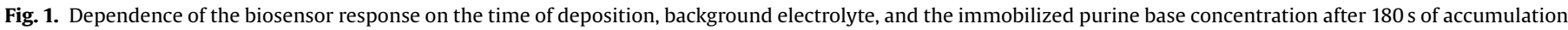

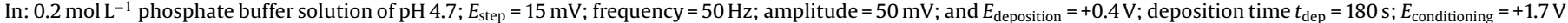
conditioning time $=30 \mathrm{~s}$.
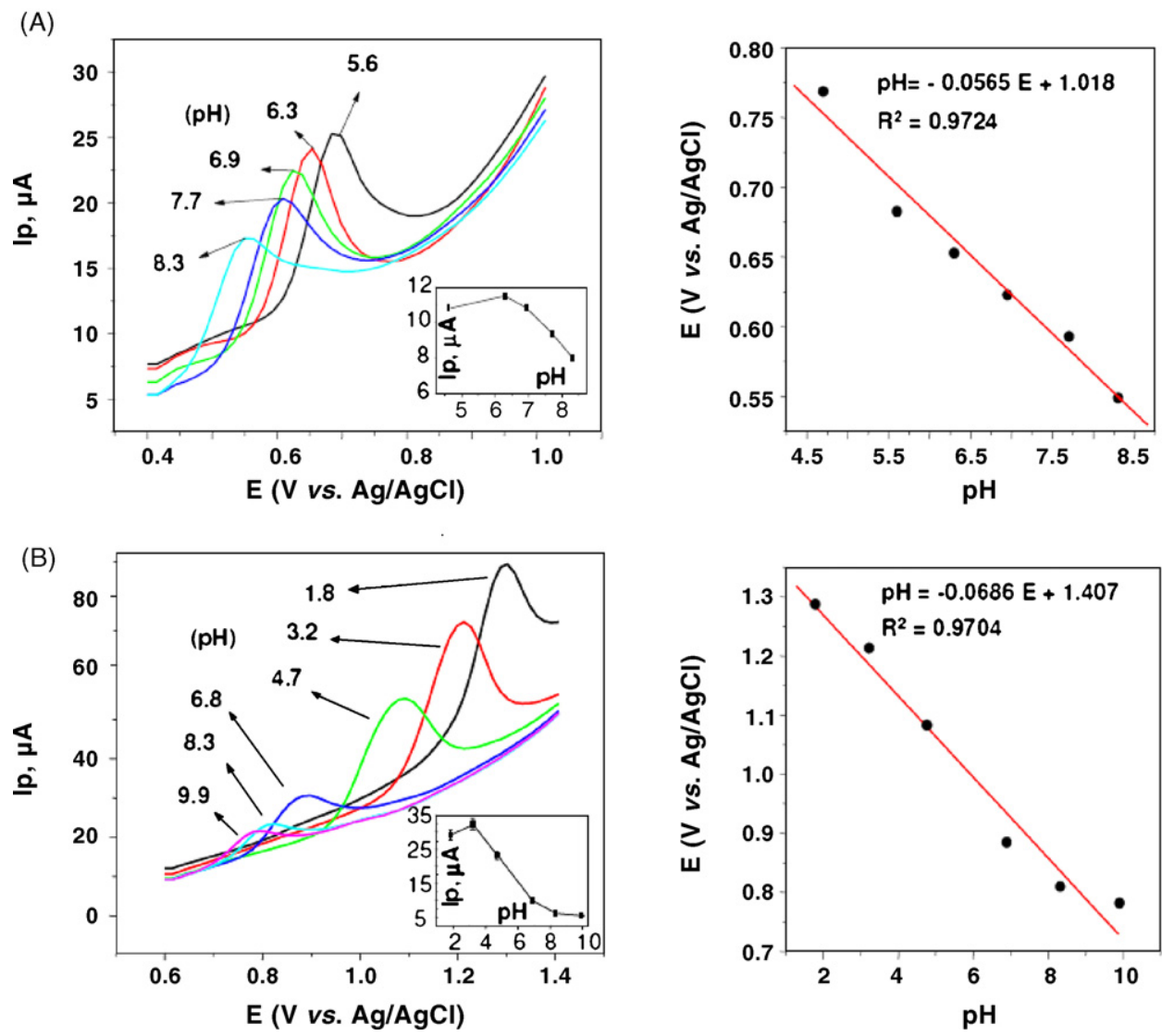

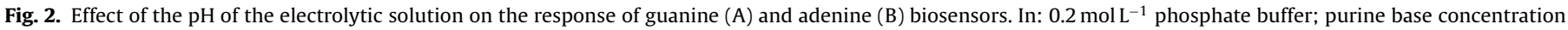
$27 \mathrm{mg} \mathrm{L}^{-1} ; E_{\mathrm{step}}=15 \mathrm{mV}$; frequency $=50 \mathrm{~Hz}$; amplitude $=50 \mathrm{mV}$; and $E_{\text {deposition }}=+0.4 \mathrm{~V}$; deposition time $t_{\mathrm{dep}}=180 \mathrm{~s} ; E_{\text {conditioning }}=+1.7 \mathrm{~V}$; conditioning time $=30 \mathrm{~s}$ 
Table 1

Antioxidant capacity of flavored water samples

\begin{tabular}{|c|c|c|c|c|c|}
\hline \multirow[t]{3}{*}{ Sample brand } & \multirow[t]{3}{*}{ Flavor } & \multicolumn{4}{|c|}{ Antioxidant capacity ( $\mathrm{mg} \mathrm{L}^{-1}$ of $\left.\mathrm{AA}\right)$} \\
\hline & & \multirow[t]{2}{*}{ Guanine biosensor ${ }^{\mathrm{a}}$} & \multicolumn{3}{|l|}{ FRAP } \\
\hline & & & $60 \mathrm{~min}$ & $150 \mathrm{~min}$ & $250 \mathrm{~min}$ \\
\hline A & Mango & $2.4 \pm 0.1$ & $3.7 \pm 0.2$ & $8.7 \pm 0.2$ & $13.1 \pm 0.5$ \\
\hline A & Lemon & $5.8 \pm 0.2$ & $3.2 \pm 0.1$ & $8.6 \pm 0.4$ & $12.1 \pm 0.9$ \\
\hline A & Strawberry & $1.6 \pm 0.1$ & $2.0 \pm 0.3$ & $5.2 \pm 0.2$ & $7.7 \pm 0.8$ \\
\hline B & Lemon & $6.1 \pm 0.3$ & $7.1 \pm 0.2$ & $18.9 \pm 0.1$ & $27.4 \pm 1.1$ \\
\hline B & Orange & $8.0 \pm 0.1$ & $4.4 \pm 0.4$ & $11.0 \pm 0.5$ & $16.6 \pm 0.7$ \\
\hline B & Apple & $5.8 \pm 0.4$ & $3.8 \pm 0.2$ & $9.6 \pm 0.4$ & $14.5 \pm 0.4$ \\
\hline $\mathrm{C}$ & Lemon & $6.3 \pm 0.3$ & $5.9 \pm 0.1$ & $11.2 \pm 0.2$ & $15.3 \pm 0.2$ \\
\hline C & Ananas/orange & $7.4 \pm 0.2$ & $7.2 \pm 0.1$ & $15.1 \pm 0.3$ & $21.3 \pm 1.1$ \\
\hline $\mathrm{D}$ & Lemon & $6.1 \pm 0.2$ & $5.7 \pm 0.2$ & $13.2 \pm 0.5$ & $19.3 \pm 0.2$ \\
\hline $\mathrm{D}$ & Apple & $2.7 \pm 0.1$ & $4.4 \pm 0.1$ & $7.9 \pm 0.1$ & $11.0 \pm 0.3$ \\
\hline $\mathrm{D}$ & Ananas & $7.7 \pm 0.4$ & $2.4 \pm 0.3$ & $5.6 \pm 0.2$ & $8.2 \pm 0.2$ \\
\hline
\end{tabular}

a Average of three measurements.

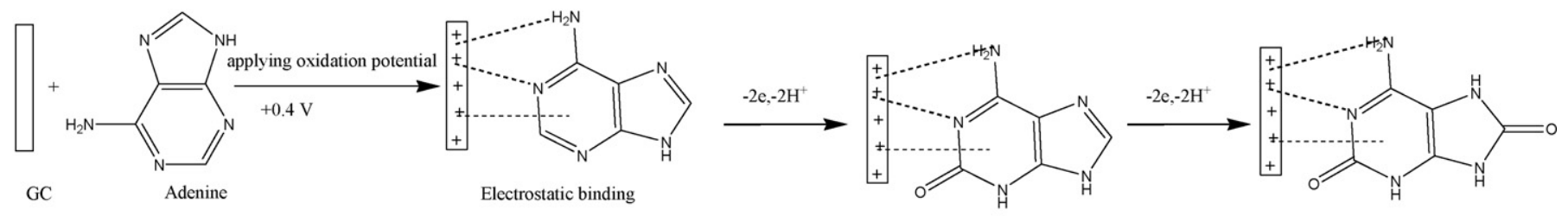

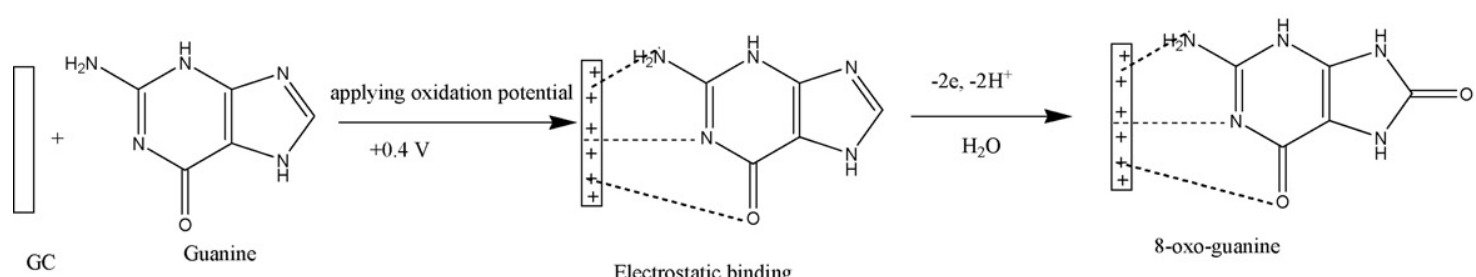

Scheme 1. Immobilization and electrochemical oxidation of guanine and adenine at a glassy carbon electrode.
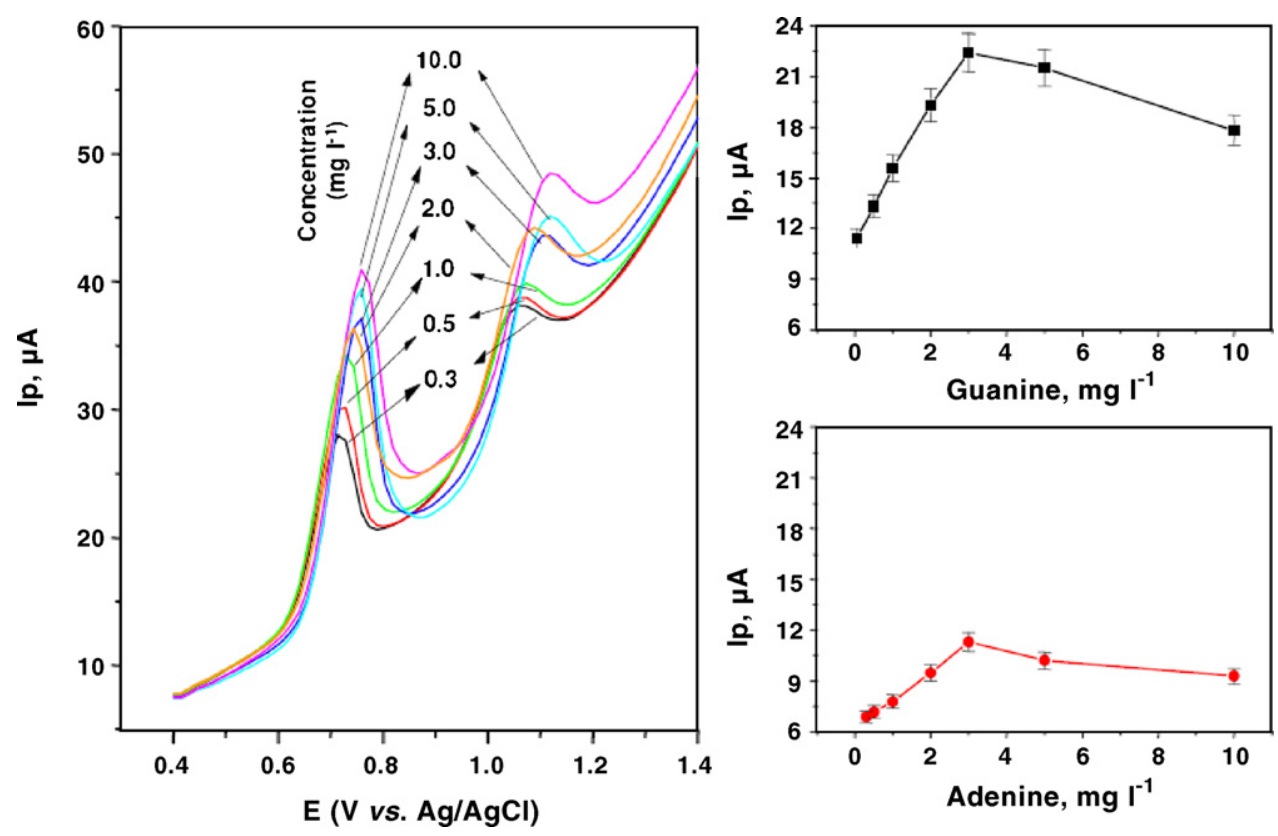

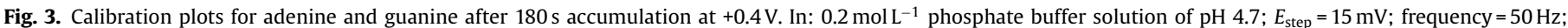
amplitude $=50 \mathrm{mV}$; and $E_{\text {deposition }}=+0.4 \mathrm{~V}$; deposition time $t_{\mathrm{dep}}=180 \mathrm{~s} ; E_{\text {conditioning }}=+1.7 \mathrm{~V}$; conditioning time $=30 \mathrm{~s}$. 
inhomogeneities, the most favorable sites being first occupied by guanine oxidation products (Brett et al., 2002a,b).

\subsection{Detection of DNA bases damage}

Studies of DNA damage induced by radical oxygen species (ROS) are of special importance because DNA is the repository of genetic information. ROS can cause cell injury especially when they are generated in excess as in oxidative stress or when the cellular antioxidant defense is impaired. One of the most reactive radical species inducing DNA lesions is the hydroxyl radical $(\bullet \mathrm{OH})$. When - $\mathrm{OH}$ is generated adjacent to DNA, it attacks both the deoxyribose sugar, and purine and pyrimidine bases resulting in intermediates radicals, which are the immediate precursors for DNA base damage (Jaruga and Dizdaroglu, 1996). An example of this effect is represented in reaction (1).

Purinebase $\left[\mathrm{Fe}^{2+}\right]+\mathrm{H}_{2} \mathrm{O}_{2} \rightarrow$ Purinebase $\left[\mathrm{Fe}^{3+}\right]+\mathrm{OH}^{-}+\cdot{ }^{\bullet} \mathrm{OH}$

In living systems many of the hydroxyl radicals are generated from the metal $(\mathrm{M})$ ion-dependent breakdown of hydrogen peroxide (Dunford, 2002; Burkitt, 2003). In the presence of ferrous or cupric ions, hydrogen peroxide is converted into the hydroxyl radical by Fenton's reaction. The Fenton-type system is important because it has been implicated as an important mediator of oxidative damage in vivo and it is of great interest in terms of reducing the possibility of mutation and consequently cancer (Burkitt, 2003) or other degenerative diseases.

At the present work, damage to DNA bases was made by exposing biosensors to hydroxyl radicals generated by Fenton reagent In a simplified way, the attack of the hydroxyl radical to guanine follows two pathways (Scheme 2). The major pathway under oxidative conditions yields 8-oxoguanine, sometimes referred to its minor tautomer 8-hydroxyguanine. Under reducing conditions, one electron is gained and one proton leads to imidazole ring opening, being the isolated product 2,6-diamino-5-formamido-4hydroxypyrimidine (Mello et al., 2006).

Biosensors of adenine or guanine or an equimolar mixture of both were prepared in solutions of 3,10 or $30 \mathrm{mgl}^{-1}$, and were placed in contact with the radical species. Although EDTA is not a biological chelating agent it was included in the solution for solubility reasons (Gutteridge et al., 1990).

Reported studies indicate that several conditions during the in vitro generation step of hydroxyl radical via Fenton reaction influence the oxidative attack to the biomolecule (Dunford, 2002). For example, the reaction time between hydroxyl radical and target molecule depends on the half-life time of the generated free radical. According to evidences, for concentrations of $\mathrm{H}_{2} \mathrm{O}_{2}$ or $\mathrm{Fe}(\mathrm{II})$ $<0.1 \mathrm{mM}$, the Fenton reaction might finish within $1 \mathrm{~s}$ (Lopes et al., 1999).

Damage to DNA bases was confirmed by a decrease in electrochemical oxidation currents (Fig. 4). As the incubation time<smiles>Nc1nc(=O)c2[nH]cnc2[nH]1</smiles>

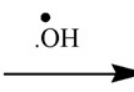

Guanine<smiles>Nc1nc(=O)c2c([nH]1)NC(O)N2</smiles>

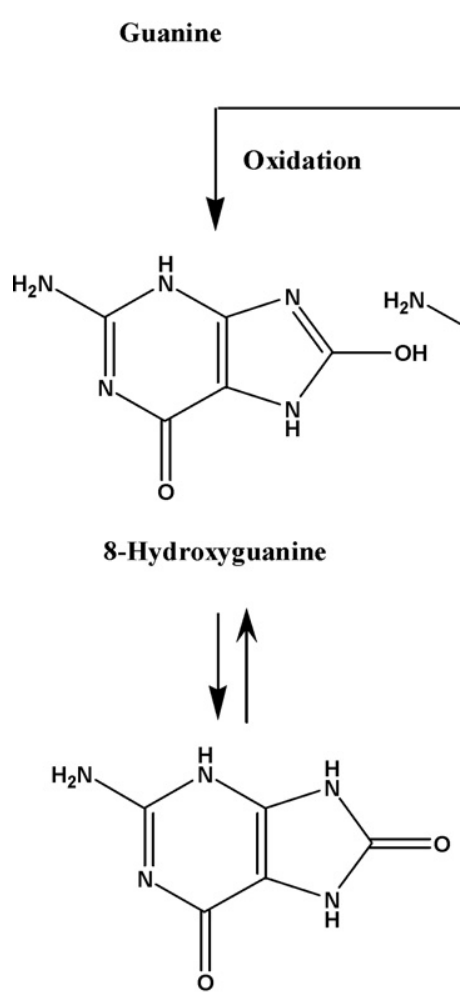

8-Oxoguanine

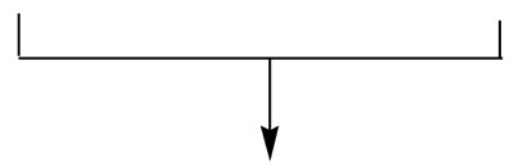<smiles>Nc1nc(=O)c(NC=O)c(N)[nH]1</smiles>

2,6-diamino-5-formamido-4-hydroxypyrimidine

Scheme 2. The reaction pathway of hydroxyl radical attack to guanine base. 

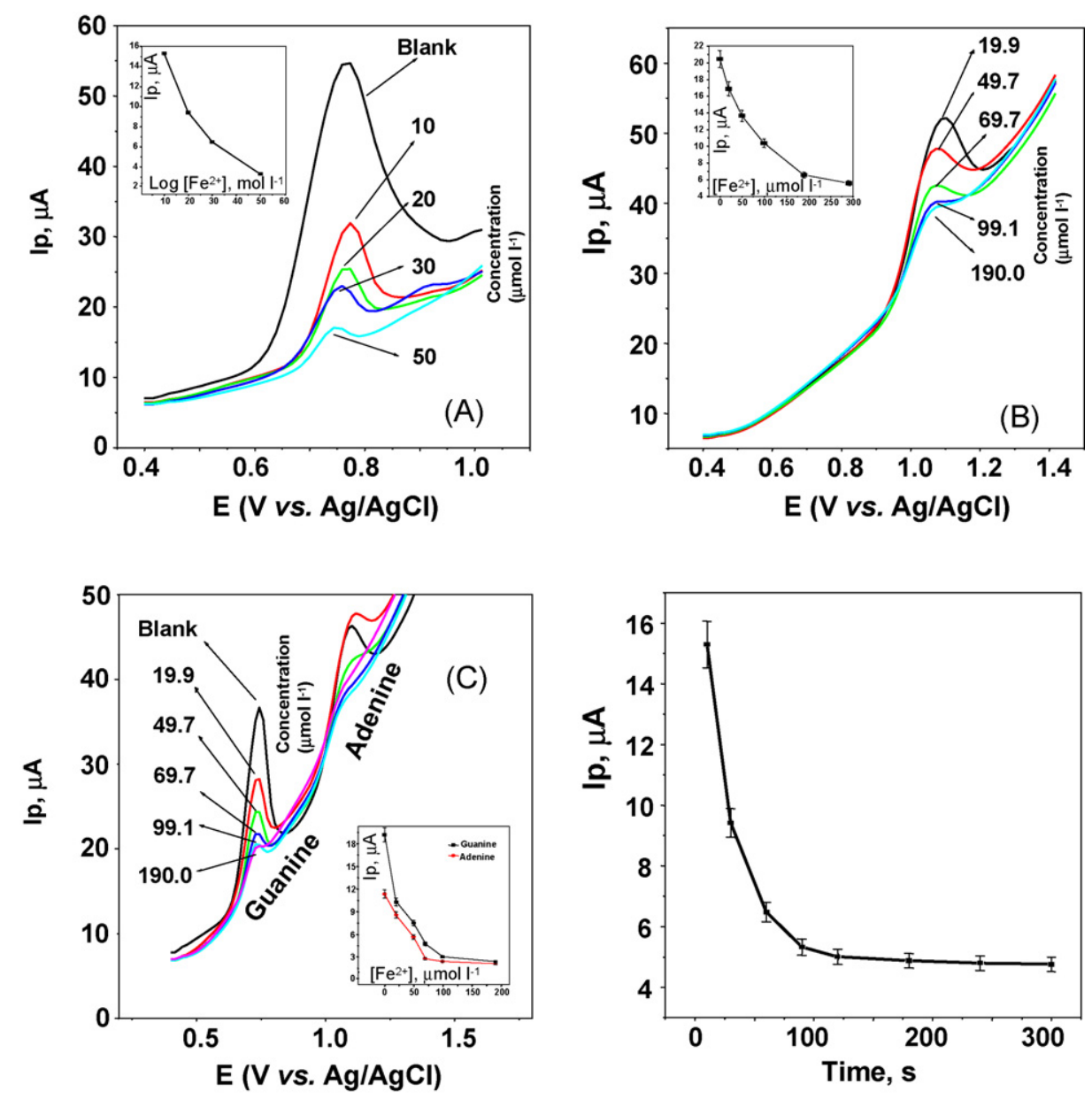

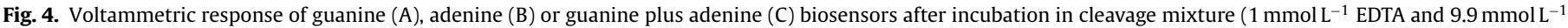

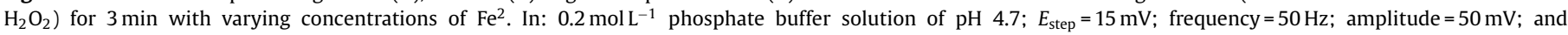

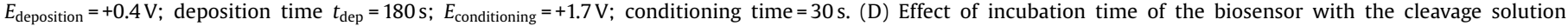
$\left(24 \mathrm{mmol} \mathrm{L}^{-1} \mathrm{Fe}^{2+}, 1.0 \mathrm{mmol} \mathrm{L}^{-1}\right.$ EDTA, and $9.9 \mathrm{mmol} \mathrm{L}^{-1} \mathrm{H}_{2} \mathrm{O}_{2}$.

increased, peak heights decreased until $120 \mathrm{~s}$. Therefore the immersion time of the biosensor on the Fenton solution was chosen for $180 \mathrm{~s}$. Another factor affecting the oxidation attack to the biomolecule was the concentration of $\mathrm{Fe}^{2+}$. The oxidation attack to the biomolecule increased exponentially with the increase of $\mathrm{Fe}^{2+}$ ions in reaction medium. The more effective biomolecule damage was observed for $200 \mu \mathrm{M}$ of $\mathrm{Fe}^{2+}$ ions. This concentration and an incubation time of $180 \mathrm{~s}$ were chosen for further studies.

\subsection{Determination of antioxidant capacity}

Dietary antioxidants modulate oxidative modifications at DNA bases provided by radical species. Their scavenging properties deactivate radicals such as ${ }^{\bullet} \mathrm{OH}$ and protect bases from oxidative damage. This protective effect is quantified in terms of antioxidant capacity. Ascorbic Acid (AA) is one of the most studied and powerful antioxidants (Dunford, 2002; Arrigoni and Tullio, 2000). It has been detected in the majority of plant cell types, organelles and in the apoplast. Under physiological conditions, AA exists mostly in the reduced form (90\% of the ascorbate pool) in leaves and chloroplasts (Arrigoni and Tullio, 2000); and its intracellular concentration can build up to millimolar range (e.g. $20 \mathrm{mM}$ in cytosol and $20-300 \mathrm{mM}$ in chloroplast stroma) (Smirnoff, 2000). AA is the main ROS detoxifying compound in aqueous phase. It has the ability of donating electrons in a wide range of enzymatic and non-enzymatic reactions, scavenging superoxide, hydroxyl radical and singlet oxygen, and reducing $\mathrm{H}_{2} \mathrm{O}_{2}$ to water via ascorbate peroxidase reaction (Foyer and Lelandais, 1996). Hydroxyl radical oxidizes AA and produces dehydroascorbic acid by abstracting proton (Noctor and Foyer, 1998). The reaction rate of ascorbic acid with hydroperoxy radical is $1.6 \times 10^{4} \mathrm{~L} \mathrm{~mol}^{-1} \mathrm{~s}^{-1}$ (Choe and Min, 2006).

Concentrations of AA were varied in Fenton incubations to investigate its protective effect against the biosensor damage promoted by hydroxyl radicals. Fig. 5 shows the influence of the antioxidant concentration on peak currents of sensor films after $\left(I_{\mathrm{pp}}\right)$ and before incubation $\left(I_{\mathrm{p}}\right)$ with Fenton reagent versus the concentration of AA. The peak current increased as the concentration of AA increased up to about $350 \mu \mathrm{M}$. The sensitivities obtained from the linear portions are (0.018) $\mu \mathrm{A} / \mathrm{mg} \mathrm{L}^{-1}, r=0.988$ and (2.027) $\mu \mathrm{A} / \mathrm{mg} \mathrm{L}^{-1}, r=0.992$ for adenine and guanine, respectively. The detection limits, estimated as three times the ratio between the blank signal and the sensitivity, are 0.10 and $0.08 \mathrm{mg} \mathrm{L}^{-1}$ for adenine and guanine biosensors, respectively. The reproducibility of the SWV response based on guanine biosensor for five repetitive measurements of a $10.0 \mathrm{mg} \mathrm{L}^{-1}$ AA solution gives an average peak height of $34.6 \mu \mathrm{A}$ and a relative standard deviation of $1.2 \%$.

Control experiments in which sensor films were incubated in absence of hydrogen peroxide (and hence in absence of hydroxyl radicals) showed no decreasing trend in ratio of peak current with increasing antioxidant concentration. In other control experiments 

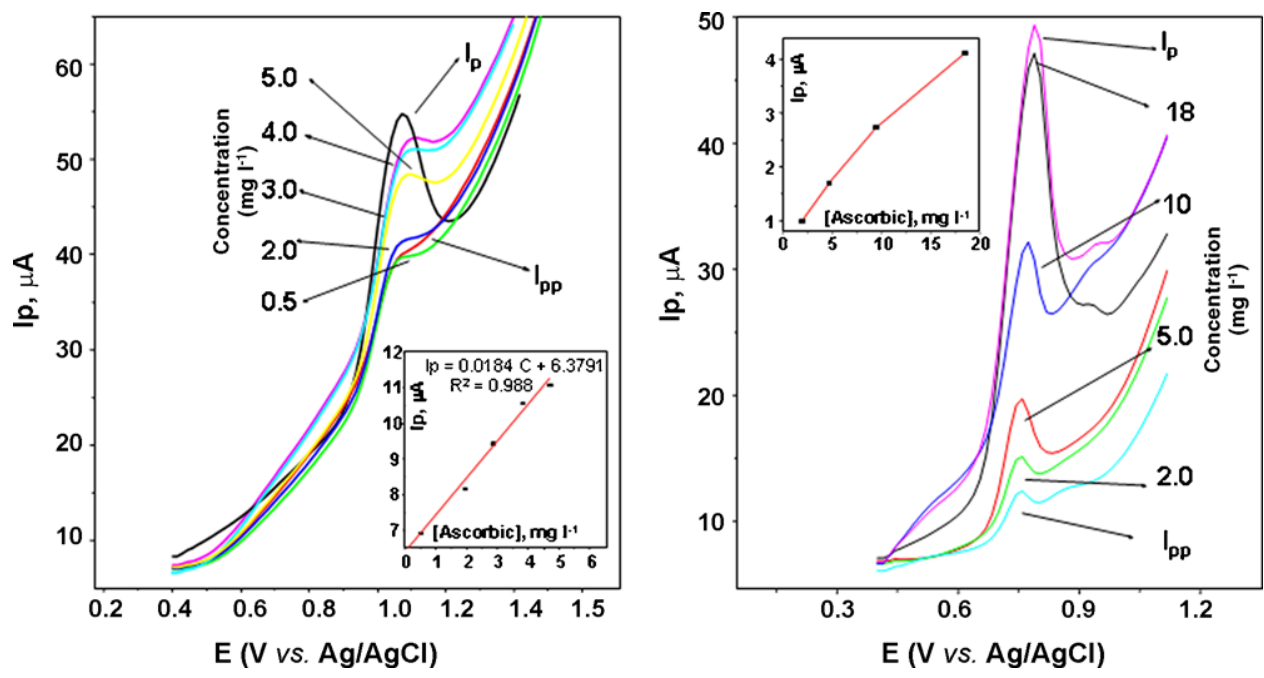

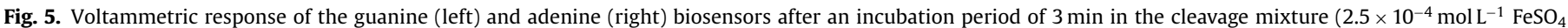

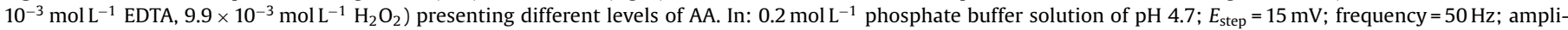
tude $=50 \mathrm{mV}$; and $E_{\text {deposition }}=+0.4 \mathrm{~V}$; deposition time $t_{\text {dep }}=180 \mathrm{~s} ; E_{\text {conditioning }}=+1.7 \mathrm{~V}$; conditioning time $=30 \mathrm{~s}$.

aimed at investigating whether antioxidant adsorption occurs in the sensor film, the sensor was incubated in $10 \mathrm{ml}$ buffer containing $1 \mathrm{mM} \mathrm{FeSO}_{4}$ and $100 \mu \mathrm{L}$ of $5.67 \mathrm{mM} \mathrm{AA}$ without $\mathrm{H}_{2} \mathrm{O}_{2}$ for $5 \mathrm{~min}$. These studies revealed small increases in peak current, slightly larger than those of the control. This resulted presumably from small amounts of electro-active AA remaining adsorbed in the biosensors even after extensive washing.

\subsection{Analytical application}

The biosensors were applied to the determination of antioxidant capacities of flavored waters. These waters have flavors and aromas deriving from natural products, which might give commercial waters some antioxidant properties. The samples considered at the present study had orange, lemon, mango, strawberry, apple, and/or ananas flavors, and provided from four different commercial brands.

The main analytical results showed different antioxidant capacities, all expressed in AA, for the commercial samples (Table 1). Lemon and orange flavors are the ones producing the higher antioxidant capacities and natural waters the lowest values. These results confirm the antioxidant properties attributed to waters by flavored waters. This may result from naturally occurring antioxidant species or from substances formed during its processing/storage. Alternatively, compounds in flavors may also exert an interfering effect at the reaction leading to hydroxyl generation.

For comparison purposes, the water samples were analyzed by FRAP method and the corresponding antioxidant capacities were expressed in terms of AA content. The chemical background of this method is completely different from that of the electrochemical one. The complex between $\mathrm{Fe}^{3+}$ and TPTZ $(2,4,6-$ tripyridyls-triazine) is prepared as $\left[\mathrm{Fe}(\mathrm{III})(\mathrm{TPTZ})_{2}\right]^{3+}$ and after reduced to $\left[\mathrm{Fe}(\mathrm{II})(\mathrm{TPTZ})_{2}\right]^{2+}$ by an antioxidant specie $(\mathrm{AA})$ in acidic media. The reduced complex has a blue color of maximum absorbance at $593 \mathrm{~nm}$. This reaction is also a kinetic process for which different time for reaction results in different antioxidant capacities. Results for 60,150 and $250 \mathrm{~min}$ are indicated in Table 1 . For the analyzed waters, signal stabilization was observed from 60 to $250 \mathrm{~min}$ or was never reached, depending on the samples.

Antioxidant capacities from the biosensor are closer to biological systems, with a nucleotide being damaged by hydroxyl radicals.
These radicals may develop oxidative attack against DNA in biological systems, and humans have no enzymatic defense against this mechanism. The resulting product is nucleotide oxidation in DNA, which may generate replication errors and subsequent misleading protein synthesis.

Therefore, the different chemical background and kinetics of both FRAP and electrochemical methods turn unsuitable a straight comparison between them. Overall, results from the biosensor and the FRAP method are comparable only in terms of relative order Results also point out lemon and orange flavors for higher antioxidant capacities. Strawberry flavors are those of smaller antioxidant capacity.

\section{Conclusion}

Immobilization of purine bases by simple electrochemical treatment of a glassy carbon surface has been established. Both hydrophobic and electrostatic interactions contribute to the adsorption of guanine and adenine nucleotides on the glassy carbon surface. The strong interaction of adenine and guanine layers with the surface of the electrode makes the confined biosensor a useful tool for the measurements of antioxidant capacity of commercial drinks. These biosensors have several advantages, such as reproducibility, constant sensitivity and avoidance of sample contamination. In addition, the chemical background of the method is much closer to the biological systems than the conventional methods reported in literature. The possibility to combine portable equipment using miniaturized disposable electrodes of low cost make them promising tools for the rapid and inexpensive evaluation of antioxidant capacity of any sample in field.

\section{References}

Arnao, M.B., Cano, A., Costa, M., 1999. Free Radic. Res. 31, S89. Arrigoni, D., Tullio, M.C., 2000. J. Plant Phys. 157, 481. Atsumi, T., Fujisawa, S., Tonosaki, K., 2005. Toxicol. In Vitro 19, 1025. Beilby, A.L., Sasaki, T.A., Stem, H.M., 1995. Anal. Chem. 67, 976. Burkitt, M.J., 2003. Prog. React. Kinet. Mech. 28, 75.

Brabec, V., 1981. Bioelectrochem. Bioenerg. 8, 437.

Brett, A.M.O., Vivan, M., Fernandes, I.R., Piedade, J.A.P., 2002a. Talanta 56 (5), 959 Brett, A.M.O., Silva, L.A., Brett, C.M.A., 2002b. Langmuir 18, 2326.

Brett, A.M.O., Diculescu, V., Piedade, J.A.P., 2002c. Bioelectrochemistry 55, 61. Brett, C.M.A., Brett, A.M.O., 1993. Electrochemistry, Principles, Methods and Applications. Oxford Science Publications Inc., New York. 
Brainina, Kh.Z., Ivanova, A.V., Sharafutadinova, E.N., Lozovskaya, E.L., Shkarina, E.I., 2007. Talanta 71, 13.

Buratti, S., Benedetti, S., Cosio, M.S., 2007. Talanta 71, 1387.

Cai, X., Rivas, G., Farıas, P.A.M., Shiraishi, H., Wang, J., Palecek, E., 1996. Electroanalysis 8, 753.

Chevion, S., Ruberts, M.A., Chevion, M., 2000. Free Radic. Bio. Med. 28, 860

Choe, E., Min, D.B., 2006. Crit. React. Food Sci. Nutr. 46, 1.

Council Directive 88/388/EEC (on the approximation of the laws of the member states relating to flavorings for use in foodstuffs and to source materials for their production) and further amendments.

Dunford, H.B., 2002. Coord. Chem. Rev. 233, 311

Erdem, A., Ozsoz, M., 2002. Electroanalysis 14, 965.

Foyer, C.H., Lelandais, M.A., 1996. J. Plant Physiol. 148, 391.

Gutteridge, J.M.C., Zsnagy, I., Maidt, L., Floyd, R.A., 1990. Arch. Biochem. Biophys. 277, 422.

Jaruga, P., Dizdaroglu, M., 1996. Nucleic Acids Res. 24, 1389.

Labuda, J., Buckova, M., Jantova, S., Stepanek, I., Surugiu, I., Danielsson, B., Mascinin M., 2000. Fres. J. Anal. Chem. 367, 364.

Laviron, E., 1982. In: Bard, A.J. (Ed.), Electroanalytical Chemistry, vol. 12. Marcel Dekker, New York, pp. 53-157.
Liu, J., Mori, A., 1993. Neuropharmacology 32, 659.

Lopes, K.B., Schulman, H.M., Hermes-Lima, 1999. Biochim. Biophys. Acta 1472, 142

Mahal, H.S., Badheka, L.P., Mukherje, T., 2001. Res. Chem. Intermed. 27, 595.

Mascini, M., Palchetti, I., Marraza, G., 2001. Fres. J. Anal. Chem. 369, 15.

McCreery, R.L., Cline, K.K., 1996. In: Kissinger, P., Heineman, W.R. (Eds.), Laboratory Techniques in Electroanalytical Chemistry. Marcel Dekker, New York.

Mello, L.D., Hernandez, S., Marrazza, G., Mascini, M., Kubota, L.T., 2006. Biosens. Bioelectron. 21, 1374.

Mocak, J., Bond, A.M., Mitchell, S., Scollary, G., 1997. Pure Appl. Chem. 69, 297.

Moreno, C.S., 2002. Food Sci. Technol. Int. 8, 121.

Noctor, G., Foyer, C.H., 1998. Ann. Rev. Plant Physiol. Plant Mol. Biol. 49, 249.

Palecek, E., 1983. In: Milazzo, G. (Ed.), Topics in Bioelectrochemistry and Bioenergetics. Wiley, London, p. 65.

Palecek, E., Fojta, M., 2001. Anal. Chem. 73, 74A.

Serafini, M., Rio, D.D., 2004. Redox Report 9, 145.

Smirnoff, N., 2000. Curr. Opin. Plant Biol. 3, 229.

Wang, J., Kawde, A.N., 2001. Anal. Chim. Acta 431, 219.

Wang, Z., Liu, D., Dong, S., 2000. Electroanalysis 12, 1419 